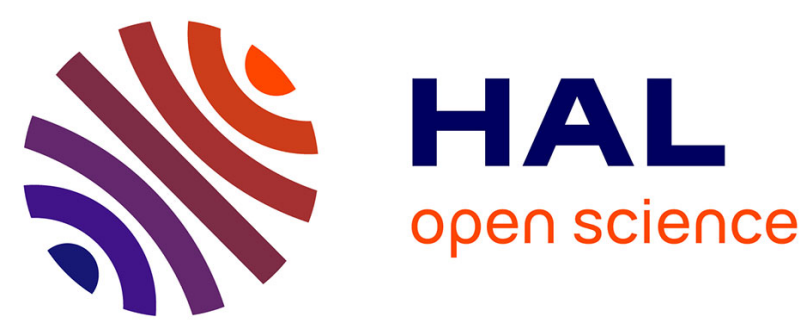

\title{
Morphologic and radiologic parameters correlating to shoulder function at diagnosis for patients with rotator cuff tear
}

Anne-Marie Cauchon, Patrice Tétreault, Clarisse Bascans, Wafa Skalli, Nicola Hagemeister

\section{To cite this version:}

Anne-Marie Cauchon, Patrice Tétreault, Clarisse Bascans, Wafa Skalli, Nicola Hagemeister. Morphologic and radiologic parameters correlating to shoulder function at diagnosis for patients with rotator cuff tear. Journal of Shoulder and Elbow Surgery, 2020, 29 (11), pp.2272-2281. 10.1016/j.jse.2020.03.027 . hal-03255712

\section{HAL Id: hal-03255712 \\ https://hal.science/hal-03255712}

Submitted on 9 Jun 2021

HAL is a multi-disciplinary open access archive for the deposit and dissemination of scientific research documents, whether they are published or not. The documents may come from teaching and research institutions in France or abroad, or from public or private research centers.
L'archive ouverte pluridisciplinaire HAL, est destinée au dépôt et à la diffusion de documents scientifiques de niveau recherche, publiés ou non, émanant des établissements d'enseignement et de recherche français ou étrangers, des laboratoires publics ou privés. 


\title{
Morphologic and radiologic parameters correlating to shoulder function at diagnosis for patients with rotator cuff tear
}

\author{
Anne-Marie Cauchon ${ }^{a}$, Patrice Tétreault, MD, MSc ${ }^{a}$, Clarisse Bascans, MSc ${ }^{b}$, \\ Wafa Skalli, PhD ${ }^{\mathrm{c}}$, Nicola Hagemeister, $\mathrm{PhD}^{\mathrm{b}}$,*
}

\author{
${ }^{a}$ University of Montreal, Montreal, Quebec, Canada \\ ${ }^{b}$ École de Technologie Supérieure, Montreal, Quebec, Canada \\ ${ }^{c}$ Arts et Métiers ParisTech, Paris, France
}

\begin{abstract}
Background: The magnetic resonance imaging (MRI) parameters used to diagnose rotator cuff tears are weakly correlated to shoulder function. Our hypothesis was that adding 3-dimensional morphologic parameters resulting from biplanar radiographs (3DXR parameters) to the MRI parameters would improve this correlation.

Methods: We assessed 52 patients with rotator cuff tears with an EOS Imaging radiographic examination, MRI study, and clinical evaluation of the shoulder, as well as the Constant score. The bones of the 52 shoulders were reconstructed 3-dimensionally, and eleven 3DXR parameters were automatically extracted. First, the trueness and reliability of these parameters were evaluated. Then, bivariate correlations between each parameter and the Constant score were made. A linear regression model was subsequently built to correlate the 11 parameters and 5 MRI findings with shoulder function at diagnosis, as assessed by the Constant score.

Results: The parameters showed good trueness and reliability of most 3DXR parameters. Supraspinatus tear extension, muscle atrophy, and the distance between the greater and deltoid tuberosities were the only parameters with a statistically significant correlation to a lower Constant score $(P<.05)$ in the bivariate study. These correlations were either weak or negligible. A regression model was successfully built with one MRI parameter and four 3DXR parameters. Correlation to function increased from $16.7 \%$ to $43.3 \%$ with this model.

Conclusion: For patients with rotator cuff tears, the combination of MRI and 3DXR parameters of the shoulder in a linear regression model improves the correlation with the Constant score (shoulder function) at diagnosis.

Level of evidence: Level IV; Case Series; Prognosis Study
\end{abstract}

Keywords: Rotator cuff tear; shoulder morphology; 3D reconstruction of shoulder; shoulder function; linear regression model; radiology of shoulder

This study was approved by the ethical committees of École de Techonologie Supérieure (study no. CE09.261) and the Centre Hospitalier de l'Université de Montréal Research Center (study no. H20100103).

*Reprint requests: Nicola Hagemeister, PhD, 900 Saint-Denis St, 11th Floor, H2X 0A9 Montreal, Quebec, Canada

E-mail address: nicola.hagemeister@etsmtl.ca (N. Hagemeister).
Rotator cuff tears (RCTs) are frequent, affecting $62 \%$ of patients aged $\geq 80$ years $^{41}$ and $20.7 \%$ of the general population. ${ }^{46}$ This pathology is responsible for $>50 \%$ of shoulder pain cases ${ }^{14}$ and can be treated surgically ${ }^{32}$ or conservatively. The conservative treatment options include physical therapy, nonsteroidal anti-inflammatory drugs, and corticosteroid injections. ${ }^{1,34}$ The clinical symptoms usually 
manifest as effort-related shoulder pain, pain at night, and weakness. ${ }^{21}$ The magnetic resonance imaging (MRI) parameters can vary from partial tearing of the supraspinatus tendon to an extended tear involving the subscapularis, supraspinatus, and infraspinatus, which results in retraction and fatty infiltration. ${ }^{19,21}$ However, these MRI parameters have a weak correlation with the patient's function and pain level. ${ }^{10,16,24,33,36}$ Specific morphologic parameters, such as the critical shoulder angle, ${ }^{30}$ have been investigated. Moor et $\mathrm{al}^{30}$ showed that an angle $<35^{\circ}$ was a predictor of glenohumeral arthritis whereas an angle $>35^{\circ}$ predicted the risk of RCT development. However, this parameter alone was not associated with the functional level.

To our knowledge, MRI and morphologic parameters have never been combined to predict shoulder function. Our hypothesis was that adding 3-dimensional (3D) morphologic parameters resulting from biplanar radiographs (3DXR parameters) to the MRI parameters would improve the correlation to shoulder function for patients with RCTs. To this end, we created a regression model to improve the correlation between a shoulder functional assessment score (Constant score) and a combination of MRI parameters and 3DXR parameters extracted from a semiautomated $3 \mathrm{D}$ reconstruction technique. Because the reconstruction technique used was developed recently, we conducted a repeatability study to ensure that the 3DXR parameters extracted from the constructed models were reproducible and accurate.

\section{Materials and methods}

This was a prospective study of patients with at least a complete tear of the supraspinatus.

\section{Data bank}

We used data from 52 participants, recruited between August 2010 and May 2013, with no less than a full-thickness tear of the supraspinatus in 1 shoulder. All patients gave their informed consent.

Every participant was assessed by a clinical examination (Neer, Hawkins, Jobe, Gerber, and scarf tests), the Constant score, an MRI study, and radiographs of the involved shoulder. The Constant score is a questionnaire that quantifies the patient's shoulder function by evaluating pain, daily living activities, range of motion, and strength. ${ }^{9}$ We used the updated version, which is adjusted for age and sex. ${ }^{9}$ The radiographs were taken with an EOS Imaging system (Paris, France), which is a biplanar, low-dose radiographic system that takes 2 orthogonal radiographic views simultaneously, allowing for subsequent 3D reconstruction of the bony structures. The participants were in a standing position, at an angle of $30^{\circ}$ with respect to the radiographic plane, with the arms at rest alongside their body. We chose this angle, which is very close to a Grashey view, because it avoids the superposition of shoulder structures on radiographs. $^{48}$

\section{D reconstruction}

The shoulder bones were reconstructed 3-dimensionally from the radiographic images using in-house software (Arts et Métiers ParisTech, Paris, France, and LIO, Montréal, Canada) together with a semiautomated technique coded on MATLAB (The MathWorks, Natick, MA, USA) and developed by Zhang ${ }^{48}$ in 2016. The operator needs to identify a few anatomic landmarks or regions on each radiograph, and a generic contour model is automatically adjusted to these landmarks (Fig. 1). In almost all cases, a slight manual adjustment is needed to best fit the participant's bones, especially in the acromial region.

\section{Evaluation of 3D reconstruction}

The trueness and reliability of the reconstruction method were assessed according to the International Organization for Standardization standard ISO 5725-2:1994. "Trueness" refers to the closeness of agreement between a reference value and a measured value. In our case, it refers to how close the $3 \mathrm{D}$ reconstruction of the proposed method is to a reference $3 \mathrm{D}$ reconstruction using computed tomography scans. "Reliability" refers to the repeatability of the method when different observers use it at different times. It gives a sense of how observers affect the result.

\section{Trueness of method using 3D reconstructions from cadavers as benchmarks}

The trueness of the reconstructed model was evaluated with the root mean square (RMS) using the shoulders from 6 cadavers. The shoulders were scanned with a Siemens Somatom Sensation 16 threedimensional scanner (Erlangen, Germany) and reconstructed with Avizo software (version 7.1; Thermo Fisher Scientific, Waltham, MA, USA). These 3D models were used as a benchmark. The 3D model of each cadaver then underwent virtual radiography with the same calibration as the EOS Imaging system, and the "ray casting" algorithm that removes soft tissues ${ }^{45}$ was used to produce digitally reconstructed radiographs (DRRs). These DRR images were reconstructed 3-dimensionally 3 times by an observer. The mean of these 3 reconstructions was compared with the model from the scanner with the RMS according to Equation 1:

$\mathrm{RMS}=\sqrt{\frac{\sum_{v_{A} \in S(A)} d^{2}\left(v_{A}, S(B)\right)}{|S(A)|}}$

where $|S(A)|$ is the number of vertices of the reconstructed model and $d(v, S(B))$ is the distance function between a random vertex $v$ of the reconstructed mesh $S(A)$ and the reference surface model $S(B){ }^{22}$ The latter was calculated as shown in Equation 2:

$d(v, S(B))=\min _{v_{B} \in S(B)}\left\|v-v_{B}\right\|$

where $v_{B}$ is a vertice from the reference surface model $S(B)$. The trueness of the 3DXR parameters extracted from the $3 \mathrm{D}$ reconstruction was evaluated with the mean bias. The bias corresponds to the difference between the value of a parameter extracted from a reconstruction and its value when measured on the reference model. Because each of the 6 cadavers was reconstructed 3 times, the trueness of a parameter corresponds to the mean of the 18 calculated biases. 


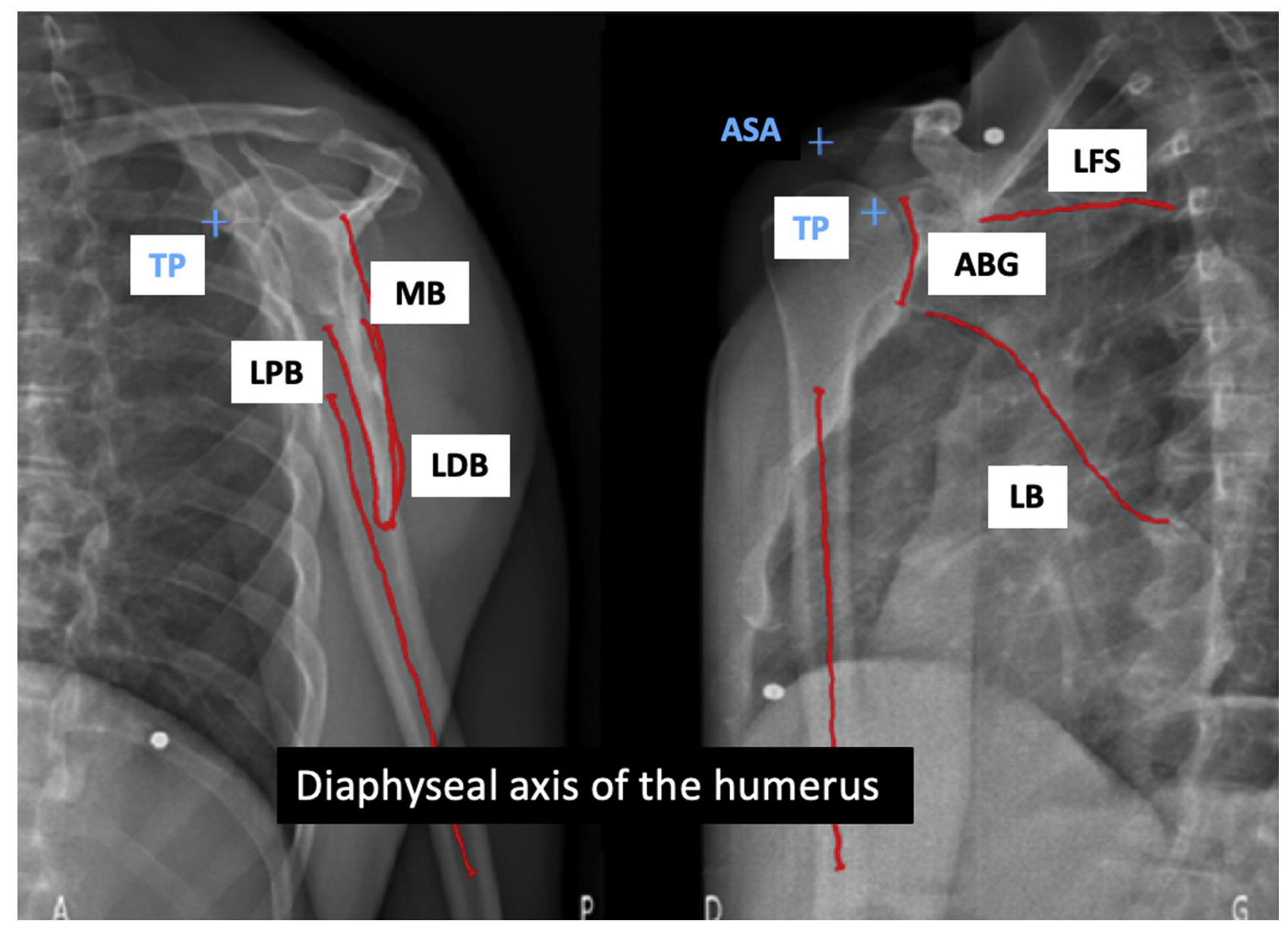

Figure 1 Identification of contours (red) and anatomic points (blue cross) used for 3-dimensional reconstruction. ASA, anterosuperior point of acromion; $L F S$, inferior line of supraspinatus fossa; $T P$, tip of coracoid process; $M B$, medial border; $A B G$, anterior border of glenoid; $L P B$, lateral proximal border; $L D B$, lateral distal border; $L B$, lateral border. (Original source: Bascans C. Évaluation morphofonctionnelle de l'épaule [master's thesis]. Montreal: École de Technologie Supérieur; 2018. Available at http://espace.etsmtl.ca/2160/.)

\section{Reliability of reconstruction method on patients' radiographs}

The reliability of the technique was assessed with another set of data containing the radiographs of 12 participants. Each shoulder was reconstructed twice by 2 observers. For each parameter, the reliability $\left(S_{R_{i}}^{2}\right)$ was calculated according to Equation 3:

$S_{R_{i}}^{2}=S_{L_{i}}^{2}+S_{r_{i}}^{2}$

where $S_{r_{i}}^{2}$ is the intraobserver variability and $S_{L_{i}}^{2}$ is the interobserver variability. The global reliability $\left(S_{R}\right)$ was calculated according to Equation 4:

$S_{R}=\sqrt{\frac{\sum_{i=1}^{n} S_{R_{i}}^{2}}{n}}$

The $S_{R}$ value was multiplied by 2 (ie, $2 \times S_{R}$ ) to estimate the $95 \%$ confidence interval $(\mathrm{CI})$ of the global reliability of a parameter.

To summarize, trueness was assessed on $3 \mathrm{D}$ reconstructions from cadaveric specimens. For each cadaver, we (1) used a 3D scanner to create a benchmark model, (2) produced DRRs, (3) reconstructed the shoulder from the DRRs 3 times, (4) determined the mean of the 3 reconstructions, (5) calculated the differences between the mean of the 3 reconstructions and the benchmark (Equation 2), and (6) calculated the RMS to evaluate the trueness of the reconstruction technique (Equation 1). Reliability was assessed on a set of radiographs from 12 patients reconstructed 3 times by 2 different operators. For each parameter, the reliability was calculated as the $95 \% \mathrm{CI}$.

\section{Regression model}

This study is a first attempt to improve our comprehension of shoulder function with MRI and 3DXR parameters. We chose to start with the simplest type of regression model: the linear regression model.

The following eleven 3DXR parameters were used to build the regression model:

- Height, width, positional inclination, morphologic inclination, and version of the glenoid

- Critical shoulder angle

- Subacromial distance

- Offset of the humeral head from the glenoid 
- Simplified path of the deltoid including (1) the distance between the middle of the lateral border of the acromion and the greater tuberosity and (2) the distance between the greater and deltoid tuberosities

- Radius of the humeral head

The inclinations are measured from a line connecting the upper and lower borders of the glenoid. The positional inclination is the angle between this line and a vector perpendicular to the ground. The morphologic inclination is the angle between this line and a vector that is perpendicular to a line connecting the trigonum spinae of the scapula and the functional center of the glenoid.

The aforementioned parameters were chosen because they are either considered risk factors for RCT development or used by

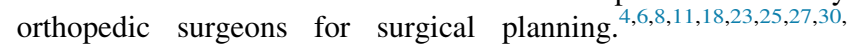
35,39,40,44 In addition, 5 MRI parameters were included in the model for the same reasons:

- Retraction of the supraspinatus tear, which corresponds to the distance between the medial margin of the tendon footprint and the tip of the torn tendon in the frontal plane

- Extension of the supraspinatus tear, measured in the sagittal plane as the distance between the pathologic area and the superior facet of the greater tuberosity ${ }^{7}$

- Muscle atrophy as assessed by Thomazeau et $\mathrm{al}^{42}$

- Fatty infiltration of the supraspinatus as measured by Goutallier et $\mathrm{al}^{20}$

- Fatty infiltration of the infraspinatus as measured by Goutallier et $\mathrm{al}^{20}$

To make sure that none of the parameters taken individually was strongly correlated to the Constant score, we began with bivariate correlations between each parameter and the Constant score. If none of the parameters has a strong correlation with the Constant score, the use of a regression model with $>1$ parameter is justified. We then used SPSS software (2016 release; IBM, Armonk, NY, USA) to build a linear regression model based on Equation 5:

$Y=\beta_{0}+\beta_{1}+\ldots+\beta_{k} X_{k}+\varepsilon$

where $\varepsilon$ is the residual value and $\beta_{O}$ is the value of $Y$ when all the dependent variables are equal to 0 . The dependent variable was shoulder function of the 52 patients affected by RCTs, as assessed by the adjusted Constant score. The Constant score was chosen because it gives a general aspect of shoulder function by assessing pain, activities of daily living, mobility, and strength of the shoulder. ${ }^{2}$ It is recommended by the European Society for Surgery of the Shoulder and the Elbow as well as by the German Society of Shoulder and Elbow Surgery. ${ }^{2}$

The independent variables were the 3DXR parameters extracted from the $3 \mathrm{D}$ reconstructions and the MRI parameters extracted from the MRI scans. The variables were added to the regression model one at a time, starting with the variable that had the strongest correlation with the dependent variable. The variables were retained if they had a significant impact on the Constant score (ie, $P<.05$ ). With every additional parameter integrated into the model, the variables previously added were reevaluated to ensure they were still significant in the new model. ${ }^{47}$

The significance of the model was validated using an analysis of variance with a threshold of $5 \%(P<.05)$. The independence of
Table I Study population

\begin{tabular}{ll}
\hline Characteristic & Data \\
\hline Patients, $\mathrm{n}$ & 52 \\
Age, mean (SD), yr & $56(7)$ \\
Sex, $\mathrm{n}(\%)$ & $32(62)$ \\
$\quad$ Male & $20(38)$ \\
$\quad$ Female & $52(100)$ \\
Supraspinatus full-thickness tear, n (\%) & $10(2)$ \\
Supraspinatus tear extension in sagittal plane, \\
$\quad$ mean (SD), mm & $26(11)$ \\
Supraspinatus tear retraction in frontal plane, & \\
$\quad$ mean (SD), mm & \\
Infraspinatus, n (\%) & $8(15)$ \\
$\quad$ Partial tear & $43(83)$ \\
$\quad$ Massive tear & $13(25)$ \\
Subscapularis, n (\%) & $8(16)$ \\
$\quad$ Partial tear & \\
$\quad$ Massive tear & $1(2)$ \\
Teres minor, $\mathrm{n}(\%)$ & $0(0)$ \\
$\quad$ Partial tear & \\
$\quad$ Massive tear & \\
\hline SD, standard deviation. &
\end{tabular}

the residual values was validated with the Durbin-Watson test, and their normal distribution was observed visually on a graphic.

\section{Results}

\section{Data bank}

Table I describes the demographic information of the 52 RCT patients included in this study.

\section{Evaluation of 3D reconstruction technique}

\section{Trueness of reconstruction model}

The trueness of the reconstruction model, as evaluated by the RMS, is presented in Table II. The RMS for the whole scapula ranged between 2.1 and $3.7 \mathrm{~mm}$, with a mean of $3.2 \mathrm{~mm}$, corresponding to 1 standard deviation. The RMS of the scapula's glenoid region ranged between 1.3 and $2.4 \mathrm{~mm}$, with a mean of $1.8 \mathrm{~mm}$. The maximal error was located in the superior part of the medial border of the glenoid. The RMS of the humerus varied between $2.0 \mathrm{~mm}$ and $4.4 \mathrm{~mm}$, which corresponds to 1 standard deviation.

\section{Trueness of extracted 3DXR parameters}

The trueness of the extracted parameters was represented by the mean bias of the reconstructions (Table III). A smaller bias indicates better trueness. The mean bias of the parameters varied between $-2.7 \mathrm{~mm}$ and $2.1 \mathrm{~mm}$ for the distances. 
Table II Evaluation of trueness of reconstruction model

\begin{tabular}{|c|c|c|c|c|c|c|c|c|}
\hline & \multicolumn{8}{|c|}{ Mean of 3 reconstructions, $\mathrm{mm}$} \\
\hline & \multicolumn{4}{|c|}{ Scapula } & \multicolumn{4}{|c|}{ Humerus } \\
\hline & \multicolumn{2}{|c|}{ Global } & \multicolumn{2}{|c|}{ Glenoid } & \multicolumn{2}{|c|}{ Global } & \multicolumn{2}{|c|}{ Superior part } \\
\hline & RMS & $\operatorname{Max}(\mathrm{AV})$ & RMS & $\operatorname{Max}(\mathrm{AV})$ & RMS & $\operatorname{Max}(\mathrm{AV})$ & RMS & $\operatorname{Max}(\mathrm{AV})$ \\
\hline \multicolumn{9}{|c|}{ Subject No. } \\
\hline 1 & 3.7 & 13.6 & 2 & 4.7 & 2.9 & 9.8 & 2.4 & 5.7 \\
\hline 2 & 3.5 & 11.3 & 1.8 & 4.1 & 2.6 & 8.9 & 2.3 & 5.1 \\
\hline 3 & 2.1 & 8.8 & 2.4 & 6.2 & 2.2 & 6.8 & 2.1 & 4.3 \\
\hline 4 & 3.1 & 10.4 & 1.3 & 2.7 & 2.2 & 5.9 & 1.8 & 4 \\
\hline 5 & 3.3 & 13 & 1.9 & 5.2 & 2 & 6.3 & 1.5 & 4 \\
\hline 6 & 3.2 & 12.4 & 1.6 & 3.7 & 3.5 & 11.8 & 2.7 & 6.9 \\
\hline Mean & 3.2 & 11.6 & 1.8 & 4.4 & 4.4 & 9.4 & 2.3 & 5.3 \\
\hline
\end{tabular}

RMS, root mean square; Max, maximum; $A V$, absolute value.

Table III Evaluation of trueness of 3DXR parameters extracted from 3D reconstruction of each cadaver as mean bias

\begin{tabular}{|c|c|c|c|c|c|c|c|}
\hline \multirow[t]{3}{*}{ 3DXR parameter } & \multicolumn{7}{|l|}{ Bias } \\
\hline & \multicolumn{6}{|c|}{ Mean of 3 reconstructions by subject } & \multirow[t]{2}{*}{ Mean } \\
\hline & 1 & 2 & 3 & 4 & 5 & 6 & \\
\hline Glenoid height, mm & 1.5 & 0.9 & -0.8 & -0.5 & 2.0 & -0.5 & 0.4 \\
\hline Glenoid width, $\mathrm{mm}$ & 3.4 & -0.5 & 1.0 & 0.0 & -0.8 & -2.1 & 0.2 \\
\hline Glenoid positional inclination, ${ }^{\circ}$ & 4 & 1 & -3 & 1 & 1 & 4 & 1 \\
\hline Glenoid morphologic inclination, ${ }^{\circ}$ & -1 & 2 & 6 & -3 & 1 & -3 & 0 \\
\hline Glenoid version, $^{\circ}$ & 2 & 1 & 2 & 3 & 1 & -1 & 1 \\
\hline Critical shoulder angle, ${ }^{\circ}$ & 5 & -3 & -3 & 3 & -1 & 4 & 1 \\
\hline Subacromial distance, $\mathrm{mm}$ & -1.1 & 1.3 & -1.5 & 2.7 & -1.9 & -1.2 & -0.3 \\
\hline Humeral head offset, $\mathrm{mm}$ & 5.5 & 1.8 & -3.4 & -1.1 & 0.6 & 9.3 & 2.1 \\
\hline Acromion-greater tuberosity distance, $\mathrm{mm}$ & -0.2 & -2.9 & -6.0 & 1.3 & -3.6 & -5.0 & -2.7 \\
\hline Greater tuberosity-deltoid tuberosity distance, $\mathrm{mm}$ & -1.0 & -1.2 & -1.5 & 1.0 & -0.8 & 2.4 & -0.2 \\
\hline Humeral head radius, $\mathrm{mm}$ & -0.4 & -1.1 & -0.1 & 0.2 & -0.4 & 0.2 & -0.3 \\
\hline
\end{tabular}

3D, 3-dimensional; 3DXR, 3-dimentionnal morphologic parameters resulting from biplanar radiographs.

\section{Reliability of extracted 3DXR parameters}

The reliability was measured by the $95 \%$ CI (Table IV), in which a smaller interval is associated with better reliability. The most repeatable parameter was glenoid version $(95 \%$ $\mathrm{CI}=1)$. The reliability of the distance between the greater and deltoid tuberosities and the critical shoulder angle was weak, with a $95 \% \mathrm{CI} \geq 5 \mathrm{~mm}$.

\section{Bivariate correlations}

Table $\mathrm{V}$ presents the correlation between the adjusted Constant score and each of the MRI and 3DXR parameters individually. Only 3 parameters were found to have a significant correlation with the Constant score: supraspinatus extension $(P=.003)$, muscle atrophy $(P=.029)$, and distance between the greater and deltoid tuberosities $(P=.041)$.
The coefficient of correlation $(r)$ indicates the strength of the correlation with each parameter and whether it is positive or negative. Correlations with a coefficient between 0.3 and 0.5 are considered weak, and those with $r<0.3$ are negligible. ${ }^{31}$ Thus, the distance between the greater and deltoid tuberosities had a negligible correlation with the adjusted Constant score, whereas muscle atrophy and the extension of the supraspinatus had weak correlations. The extension of the supraspinatus tear had the strongest correlation with the Constant score.

\section{Multiple regression model}

The multiple regression model was successfully built starting with the variable that had the strongest bivariate correlation with the Constant score: the extension of the supraspinatus tear. The final model contained one MRI 
Table IV Ninety-five percent CIs for eleven 3DXR parameters

\begin{tabular}{|c|c|}
\hline 3DXR parameter & $95 \% \mathrm{CI}$ \\
\hline Glenoid height, mm & 2.8 \\
\hline Glenoid width, $\mathrm{mm}$ & 2.0 \\
\hline Glenoid positional inclination, ${ }^{\circ}$ & 5 \\
\hline Glenoid morphologic inclination, ${ }^{\circ}$ & 5 \\
\hline Glenoid version, $^{\circ}$ & 1 \\
\hline Critical shoulder angle, ${ }^{\circ}$ & 4 \\
\hline Subacromial distance, $\mathrm{mm}$ & 2.8 \\
\hline Humeral head offset, $\mathrm{mm}$ & 2.5 \\
\hline Acromion-greater tuberosity distance, $\mathrm{mm}$ & 5.0 \\
\hline Greater tuberosity-deltoid tuberosity distance, $\mathrm{mm}$ & 6.5 \\
\hline Humeral head radius, $\mathrm{mm}$ & 1.3 \\
\hline
\end{tabular}

$C I$, confidence interval; 3DXR, 3-dimentionnal morphologic parameters resulting from biplanar radiographs.

parameter and four 3DXR parameters that had a significant impact on the Constant score when combined, as seen in Equation 6:

$$
\begin{gathered}
Y=167.43+(-4.3) \times X_{1}+(-1.0) \times X_{2}+1.3 \times X_{3} \\
+11 \times X_{4}+(-1.8) \times X_{5}+\varepsilon
\end{gathered}
$$

where $X_{1}$ is extension of the supraspinatus; $X_{2}$, distance between the greater and deltoid tuberosities; $X_{3}$, offset of the humeral head from the glenoid; $X_{4}$, glenoid version; and $X_{5}$, subacromial distance.

Each of the model's significant parameters and its coefficient are presented in Table VI. The $R^{2}$ coefficient of this model is 0.433 , which means that the model explains $43.3 \%$ of the variability of the adjusted Constant score among patients with RCTs at diagnosis. The column showing variation in $R^{2}$ indicates the percentage change in the Constant score, as explained by each parameter. Thus, the extension of the supraspinatus explains $16.7 \%$ of the variability, the distance between the greater and deltoid tuberosities explains $7.9 \%$, and so on. Every parameter significantly contributes to the model because the $P$ value of the variation of $R^{2}$ is below the significance threshold of .05 for all parameters.

\section{Discussion}

The MRI parameters currently used to evaluate RCTs are moderately correlated with function and pain levels. ${ }^{10,16,24,36}$ In this study, we were able to validate a 3D reconstruction technique for the shoulder bones. From this reconstruction, 3DXR parameters were automatically extracted. The trueness and reliability of these parameters were successfully evaluated. The distance between the greater and deltoid tuberosities had the best trueness $(-0.3$ $\mathrm{mm})$ but the worst reliability $(6.5 \mathrm{~mm})$. This finding could be caused by the poor visibility of the deltoid insertion on the humerus on radiographs. All the other parameters showed good trueness and reliability. Our hypothesis was
Table V Bivariate correlations with Constant score

\begin{tabular}{lll}
\hline Parameter & $\begin{array}{l}\text { Correlation } \\
\text { coefficient }(r)\end{array}$ & $\begin{array}{l}P \\
\text { value }\end{array}$ \\
\hline Supraspinatus extension & -0.409 & $.003^{*}$ \\
Muscle atrophy & -0.303 & $.029^{*}$ \\
Distance between greater and & -0.285 & $.041^{*}$ \\
$\quad$ deltoid tuberosities & & \\
Fatty involution of supraspinatus & -0.21 & .128 \\
Fatty involution of infraspinatus & -0.192 & .173 \\
Supraspinatus retraction & -0.188 & .183 \\
Distance between acromion and & -0.161 & .255 \\
$\quad$ greater tuberosity & & \\
Subacromial distance & -0.126 & .375 \\
Glenoid height & -0.125 & .377 \\
Glenoid length & -0.117 & .410 \\
Glenoid version & 0.102 & .472 \\
Humeral head radius & -0.095 & .505 \\
Glenoid morphologic inclination angle & -0.086 & .542 \\
Glenoid positional inclination angle & -0.086 & .545 \\
Humeral head offset from glenoid & 0.062 & .662 \\
Critical shoulder angle & 0.002 & .988 \\
\hline * Statistically significant $(P<.05)$. & &
\end{tabular}

that these 3DXR parameters could explain, at least in part, the shoulder functional level by means of a regression model for patients with at least a complete tear of the supraspinatus.

According to the results of the bivariate correlations, none of the parameters had a strong correlation with the Constant score. This finding supports the relevance of building a linear regression model with $>1$ parameter to explain the Constant score.

Among the 5 commonly used MRI parameters tested in this study, only 1 parameter (supraspinatus extension) had a significant $(P=.03)$ but weak $(r=-0.41$, so $0.3<|r|<$ $0.5)$ correlation with the adjusted Constant score. In the regression model, this parameter only explains $16.7 \%$ of the Constant score variability if used alone. Adding four 3DXR parameters (distance between the greater and deltoid tuberosities, glenoid version, humeral head offset, and subacromial distance) explains $43.3 \%$ of the Constant score's variability, confirming that shoulder morphology plays a role in shoulder function in RCT cases.

According to our results, a greater humeral head offset (ie, the distance between the functional center of the glenoid and the greater tuberosity of the humerus) and a more anteriorly tilted glenoid were associated with a better Constant score. No association between these 2 parameters and shoulder function is found in the literature. Nevertheless, Iannotti et $\mathrm{al}^{27}$ (1992) determined that a larger offset implies that the greater tuberosity is farther from the glenoid, giving the deltoid a larger moment arm. This could allow the deltoid to compensate for the torn tendons and explain why a larger offset was associated with a better Constant score in our study. 
Table VI Significant parameters and their coefficients

\begin{tabular}{|c|c|c|c|c|c|}
\hline Parameter & Coeff $\beta_{i}$ & Coeff stand & Sig ( $P$ value) & Variation of $R^{2}$ & Sig $\operatorname{var} R^{2}$ \\
\hline$X_{1}:$ extension of supraspinatus & -4.3 & -0.52 & $<.001$ & 0.167 & 0.003 \\
\hline$X_{2}:$ distance between greater and deltoid tuberosities & -1.0 & -0.49 & $<.001$ & 0.079 & 0.028 \\
\hline$X_{3}:$ offset of humeral head from glenoid & -1.3 & 0.26 & .035 & 0.065 & 0.038 \\
\hline$X_{4}:$ glenoid version & 11 & 0.31 & .015 & 0.0563 & 0.046 \\
\hline$X_{5}:$ subacromial distance & -1.8 & -0.27 & .026 & 0.066 & 0.026 \\
\hline
\end{tabular}

Coeff, coefficient; Coeff stand; standardized coefficient; Sig ( $P$ value), P value of the coefficients; Sig var $R^{2}, P$ value of the variation of $R^{2}$.

A

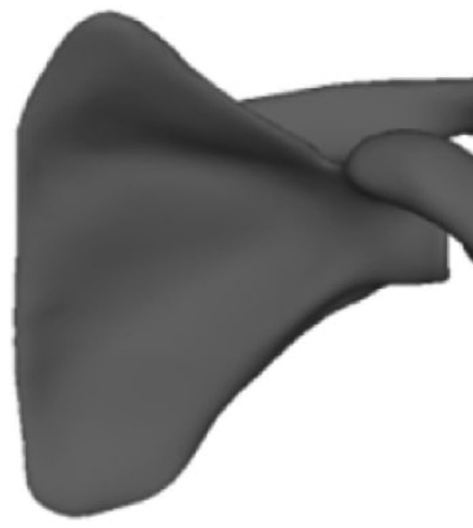

B

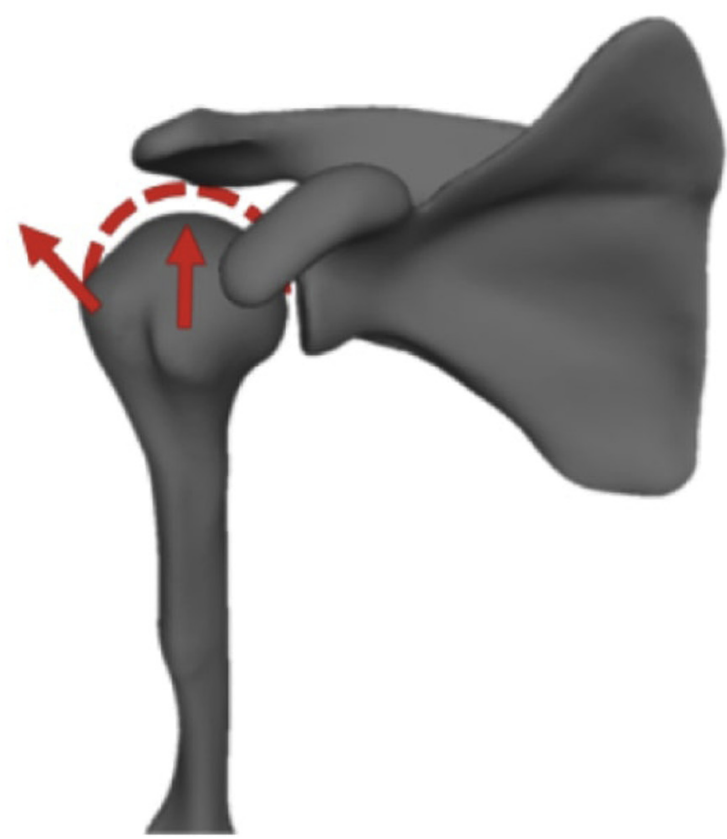

Figure 2 Hypothesized impact of subacromial distance on shoulder function. (A) Left shoulder with subacromial distance of 0.80 mm. (B) Right shoulder with subacromial distance of $11.1 \mathrm{~mm}$. When the humeral head is farther below the acromion, the deltoid first lift it to the position illustrated by the dashed lines. It then applies the force illustrated by the left arrow to abduct the arm. (Original source: Bascans C. Évaluation morpho-fonctionnelle de l'épaule [master's thesis]. Montreal: École de Technologie Supérieur; 2018. Available at http:// espace.etsmtl.ca/2160/.) $)^{3}$

We also demonstrated that the extension of the supraspinatus tear, the subacromial distance, and the distance between the greater and deltoid tuberosities have a negative correlation with the Constant score. As expected, on the basis of the literature, a larger extension of the complete supraspinatus tear was associated with a lower Constant score. $^{38}$ This association is understandable because a complete tear points to greater loss of function of this muscle. Supraspinatus atrophy was not in the final regression model even though it had a significant bivariate correlation with the Constant score. Previous research showed that atrophy of the supraspinatus correlates with its extension, ${ }^{37}$ and in our study, the bivariate correlation between these 2 parameters was significant $(P=.001)$. Because the extension of the supraspinatus tear was added first to the regression model, the atrophy did not provide significant additional information and was not retained by the model.
Contrary to our results, studies have concluded that a larger subacromial distance is associated with better shoulder function. ${ }^{12,13,17}$ To explain our results, we hypothesize that a small subacromial space could be the consequence of the supraspinatus tendon tear and upward migration of the humeral head. Therefore, when the subacromial space is larger, the head of the humerus is farther below the acromion and the deltoid needs to lift it before being able to elevate the arm. This would reduce the deltoid's functional capacity (Fig. 2). Moreover, our study population had a mean subacromial distance that is quite substantial $(6.9 \pm 2.6 \mathrm{~mm})$ compared with other studies' RCT patients. ${ }^{28}$ This could explain why the subacromial distance did not affect function negatively. Of note, only 3 participants showed signs of erosion of the acromion.

To our knowledge, there is no specific correlation between the adjusted Constant score and the distance between the greater and deltoid tuberosities. Indeed, its 
impact on shoulder function has yet to be studied. The distance between the greater tuberosity and deltoid tuberosity corresponds to the distance between the insertion of the deltoid on the lateral humerus and the insertion of the supraspinatus and infraspinatus on the greater tuberosity. We believe that when this distance is smaller, the deltoid's muscle fibers are more aligned with the fibers of the supraspinatus and infraspinatus, allowing better compensation when the tendons are torn. A lower insertion point of the deltoid muscle on the humerus, on the contrary, implies a more vertical orientation of the muscle fibers and an insertion farther below the center of rotation of the humeral head, thereby possibly causing an antagonistic effect with the rotator cuff.

As expected from the literature, the critical shoulder angle did not significantly increase the correlation of the linear regression model with shoulder function. In other studies, the critical shoulder angle was strongly associated with the risk of RCT development and the risk of retear after surgical repair of the rotator cuff but was not correlated with shoulder function once the tear was present. 15,30,44

There are some limitations in our study. The use of the Constant score is one limitation. Because it is mainly used to assess shoulder function before and after surgery, there is no threshold for good or bad function at a certain time point. Furthermore, the Constant score is a global evaluation of the shoulder. It would be interesting to build different regression models to explain specific aspects of shoulder function, such as pain and shoulder mobility. Another limitation is that the regression model was built with parameters of variable reliability because they were extracted from a reconstruction method that was not fully automated. Moreover, 14 parameters were considered to build the regression model, and 5 of them were retained in the final model. Other parameters could have been considered initially, such as the length of the acromion. This parameter could have an important impact on the shoulder's range of motion according to Humphries et $\mathrm{al}^{26}$ (2017) and has been associated with RCTs in several studies. ${ }^{5,29,43}$

An important part of the variability in the Constant score results remains unexplained. Therefore, other types of correlations and other parameters should be tested. Muscular parameters, such as the muscular volume of the deltoid and cuff, could have an impact on shoulder function as well and could be added to the regression model in the future. Our regression model could also be applied to patients presenting with simple tendinitis or partial tearing of the supraspinatus and pathologies unrelated to the rotator cuff to find a correlation between function and 3DXR parameters.

\section{Conclusion}

We were able to validate a semiautomated 3D reconstruction technique that automatically computes $3 \mathrm{D}$ morphologic parameters resulting from biplanar radiographs (3DXR) of the shoulder bones. We were also able to build a regression model that explains $43.3 \%$ of the variability in the Constant score at diagnosis for patients with RCTs. This study is a first attempt to enhance our comprehension of shoulder function using both MRI and 3DXR parameters. Further research would allow our comprehension to keep improving.

\section{Acknowledgments}

The authors thank Kathleen Beaudoin for English editing of this article.

\section{Disclaimer}

This study was supported by the Natural Sciences and Engineering Research Council of Canada (grant no. RGPIN-2017-04080).

The authors, their immediate families, and any research foundations with which they are affiliated have not received any financial payments or other benefits from any commercial entity related to the subject of this article.

\section{References}

1. Agarwalla A, Cvetanovich GL, Gowd AK, Romeo AA, Cole BJ, Verma NN, et al. Epidemiological analysis of changes in clinical practice for full-thickness rotator cuff tears from 2010 to 2015. Orthop J Sports Med 2019;7:2325967119845912. https://doi.org/10.1177/ 2325967119845912.

2. Angst F, Schwyzer H-K, Aeschlimann A, Simmen BR, Goldhahn J. Measures of adult shoulder function: Disabilities of the Arm, Shoulder, and Hand Questionnaire (DASH) and its short version (QuickDASH), Shoulder Pain and Disability Index (SPADI), American Shoulder and Elbow Surgeons (ASES) Society standardized shoulder assessment form, Constant (Murley) score (CS), Simple Shoulder Test (SST), Oxford Shoulder Score (OSS), Shoulder Disability Questionnaire (SDQ), and Western Ontario Shoulder Instability Index (WOSI). Arthritis Care Res (Hoboken) 2011;63(Suppl 11):S174-88. https://doi. org/10.1002/acr.20630

3. Bascans C. Évaluation morpho-fonctionnelle de l'épaule [Morphofunctionnal shoulder assessment] [French]. 2018. http://espace.etsmtl. ca/2160/. Accessed February 6, 2020.

4. Beeler S, Hasler A, Götschi T, Meyer DC, Gerber C. Critical shoulder angle: acromial coverage is more relevant than glenoid inclination. J Orthop Res 2019;37:205-10. https://doi.org/10.1002/jor.24053

5. Bigliani L. The morphology of the acromion and its relationship to rotator cuff tears. Orthop Trans 1986;228.

6. Blonna D, Giani A, Bellato E, Mattei L, Caló M, Rossi R, et al. Predominance of the critical shoulder angle in the pathogenesis of degenerative diseases of the shoulder. J Shoulder Elbow Surg 2016;25:1328-36. https://doi.org/10.1016/j.jse.2015.11. 059 
7. Bureau NJ, Deslauriers M, Lepage-Saucier M, Rouleau DM, Roy A, Tétreault $\mathrm{P}$, et al. Rotator cuff tear morphologic parameters at magnetic resonance imaging: relationship with muscle atrophy and fatty infiltration and patient-reported function and health-related quality of life. J Comput Assist Tomogr 2018;42:784-91. https://doi.org/10.1097/ RCT.0000000000000740

8. Cay N, Tosun Ö, Doğan M, Karaoğlanoğlu M, Bozkurt M. The effect of morphometric relationship between the glenoid fossa and the humeral head on rotator cuff pathology. Acta Orthop Traumatol Turc 2012;46:325-31. https://doi.org/10.3944/aott.2012.2807

9. Constant CR, Gerber C, Emery RJH, Søjbjerg JO, Gohlke F, Boileau P. A review of the Constant score: modifications and guidelines for its use. J Shoulder Elbow Surg 2008;17:355-61. https://doi.org/10.1016/j. jse.2007.06.022

10. Curry EJ, Matzkin EE, Dong Y, Higgins LD, Katz JN, Jain NB. Structural characteristics are not associated with pain and function in rotator cuff tears: the ROW Cohort Study. Orthop J Sports Med 2015; 3:2325967115584596. https://doi.org/10.1177/2325967115584596.

11. Daggett M, Werner B, Collin P, Gauci M-O, Chaoui J, Walch G. Correlation between glenoid inclination and critical shoulder angle: a radiographic and computed tomography study. J Shoulder Elbow Surg 2015;24:1948-53. https://doi.org/10.1016/j.jse.2015.07.013

12. de Oliveira França F, Godinho AC, Ribeiro EJS, Falster L, Búrigo LEG, Nunes RB. Evaluation of the acromiohumeral distance by means of magnetic resonance imaging umerus. Rev Bras Ortop 2016;51:169-74. https://doi.org/10.1016/j.rboe.2016.01.008

13. Deranlot J, Herisson O, Nourissat G, Zbili D, Werthel JD, Vigan M, et al. Arthroscopic subacromial spacer implantation in patients with massive irreparable rotator cuff tears: clinical and radiographic results of 39 retrospectives cases. Arthroscopy 2017;33:1639-44. https://doi. org/10.1016/j.arthro.2017.03.029

14. Dinnes J, Loveman E, McIntyre L, Waugh N. The effectiveness of diagnostic tests for the assessment of shoulder pain due to soft tissue disorders: a systematic review. Health Technol Assess 2003;7:iii. 1-166. https://doi.org/10.3310/hta7290.

15. Docter S, Khan M, Ekhtiari S, Veillette C, Paul R, Henry P, et al. The relationship between the critical shoulder angle and the incidence of chronic, full-thickness rotator cuff tears and outcomes after rotator cuff repair: a systematic review. Arthroscopy 2019;35:3135-43.e4 https://doi.org/10.1016/j.arthro.2019.05.044

16. Dunn WR, Kuhn JE, Sanders R, An Q, Baumgarten KM, Bishop JY, et al. Symptoms of pain do not correlate with rotator cuff tear severity: a cross-sectional study of 393 patients with a symptomatic atraumatic full-thickness rotator cuff tear. J Bone Joint Surg Am 2014;96:793800. https://doi.org/10.2106/JBJS.L.01304

17. Ellman H, Hanker G, Bayer M. Repair of the rotator cuff. End-result study of factors influencing reconstruction. J Bone Joint Surg Am 1986;68:1136-44.

18. Engelhardt C, Farron A, Becce F, Place N, Pioletti DP, Terrier A. Effects of glenoid inclination and acromion index on humeral head translation and glenoid articular cartilage strain. J Shoulder Elbow Surg 2017;26:157-64. https://doi.org/10.1016/j.jse.2016.05.031

19. Fermont AJM, Wolterbeek N, Wessel RN, Baeyens J-P, de Bie RA. Prognostic factors for successful recovery after arthroscopic rotator cuff repair: a systematic literature review. J Orthop Sports Phys Ther 2014;44:153-63. https://doi.org/10.2519/jospt.2014.4832

20. Goutallier D, Postel JM, Bernageau J, Lavau L, Voisin MC. Fatty muscle degeneration in cuff ruptures. Pre- and postoperative evaluation by CT scan. Clin Orthop Relat Res 1994:78-83.

21. Greene WB. Netter's orthopaedics. 1st ed. Philadelphia: Saunders Elsevier; 2006

22. Heimann T, van Ginneken B, Styner MA, Arzhaeva Y, Aurich V, Bauer C, et al. Comparison and evaluation of methods for liver segmentation from CT datasets. IEEE Trans Med Imaging 2009;28:125165. https://doi.org/10.1109/TMI.2009.2013851

23. Heuberer PR, Plachel F, Willinger L, Moroder P, Laky B, Pauzenberger L, et al. Critical shoulder angle combined with age predict five shoulder pathologies: a retrospective analysis of 1000 cases. BMC Musculoskelet Disord 2017;18:259. https://doi.org/10. 1186/s12891-017-1559-4

24. Hsu JE, Tang A, Matsen FA 3rd. Patient self-assessed shoulder comfort and function and active motion are not closely related to surgically documented rotator cuff tear integrity. J Shoulder Elbow Surg 2017; 26:1938-42. https://doi.org/10.1016/j.jse.2017.05.011

25. Hughes RE, Bryant CR, Hall JM, Wening J, Huston LJ, Kuhn JE, et al. Glenoid inclination is associated with full-thickness rotator cuff tears. Clin Orthop Relat Res 2003:86-91. https://doi.org/10.1097/00003086200302000-00016

26. Humphries A, Cirovic S, Shaheen AF. Shoulder bone geometry affects the active and passive axial rotational range of the glenohumeral joint. Am J Sports Med 2017;45:3010-9. https://doi.org/10.1177/ 0363546517716926

27. Iannotti JP, Gabriel JP, Schneck SL, Evans BG, Misra S. The normal glenohumeral relationships. An anatomical study of one hundred and forty shoulders. J Bone Joint Surg Am 1992;74:491-500.

28. Matcuk GR Jr, Moin P, Cen S. Shoulder measurements on MRI: statistical analysis of patients without and with rotator cuff tears and predictive modeling. Clin Anat 2020;33:173-86. https://doi.org/10. 1002/ca.23422

29. Mohamed RE, Abo-Sheisha DM. Assessment of acromial morphology in association with rotator cuff tear using magnetic resonance imaging. Egypt J Radiol Nucl Med 2014;45:169-80. https://doi.org/10.1016/j. ejrnm.2013.11.013

30. Moor BK, Wieser K, Slankamenac K, Gerber C, Bouaicha S. Relationship of individual scapular anatomy and degenerative rotator cuff tears. J Shoulder Elbow Surg 2014;23:536-41. https://doi.org/10.1016/ j.jse.2013.11.008

31. Mukaka MM. Statistics corner: a guide to appropriate use of correlation coefficient in medical research. Malawi Med J 2012;24: 69-71.

32. Nathani A, Smith K, Wang T. Partial and full-thickness RCT: modern repair techniques. Curr Rev Musculoskelet Med 2018;11:113-21. https://doi.org/10.1007/s12178-018-9465-4

33. Nové-Josserand L, Saffarini M, Hannink G, Carrillon Y. Influence of pre-operative tear size and tendon retraction on repair outcomes fo isolated subscapularis tears. Int Orthop 2016;40:2559-66. https://doi. org/10.1007/s00264-016-3299-8

34. Oh LS, Wolf BR, Hall MP, Levy BA, Marx RG. Indications for rotator cuff repair: a systematic review. Clin Orthop Relat Res 2007;455:5263. https://doi.org/10.1097/BLO.0b013e31802fc175

35. Pandey V, Vijayan D, Tapashetti S, Agarwal L, Kamath A, Acharya K, et al. Does scapular morphology affect the integrity of the rotator cuff? J Shoulder Elbow Surg 2016;25:413-21. https://doi.org/10.1016/j.jse. 2015.09.016

36. Reyes BA, Hull BR, Kurth AB, Kukowski NR, Mulligan EP, Khazzam MS. Do magnetic resonance imaging characteristics of fullthickness rotator cuff tears correlate with sleep disturbance? Orthop J Sports Med 2017;5:2325967117735319. https://doi.org/10.1177/ 2325967117735319 .

37. Rulewicz GJ, Beaty S, Hawkins RJ, Kissenberth MJ. Supraspinatus atrophy as a predictor of rotator cuff tear size: an MRI study utilizing the tangent sign. J Shoulder Elbow Surg 2013;22:e6-10. https://doi. org/10.1016/j.jse.2012.10.048

38. Sambandam SN, Khanna V, Gul A, Mounasamy V. Rotator cuff tears: an evidence based approach. World J Orthop 2015;6:902-18. https:/ doi.org/10.5312/wjo.v6.i11.902

39. Saygi B, Karahan N, Karakus O, Demir AI, Ozkan OC, SoyluBoy FN. Analysis of glenohumeral morphological factors for anterior shoulder instability and rotator cuff tear by magnetic resonance imaging. J Orthop Surg (Hong Kong) 2018;26:2309499018768100. https://doi.org/10.1177/2309499018768100.

40. Tétreault P, Krueger A, Zurakowski D, Gerber C. Glenoid version and rotator cuff tears. J Orthop Res 2004;22:202-7. https://doi.org/10. 1016/S0736-0266(03)00116-5 
41. Teunis T, Lubberts B, Reilly BT, Ring D. A systematic review and pooled analysis of the prevalence of rotator cuff disease with increasing age. J Shoulder Elbow Surg 2014;23:1913-21. https:// doi.org/10.1016/j.jse.2014.08.001

42. Thomazeau H, Rolland Y, Lucas C, Duval JM, Langlais F, Atrophy of the supraspinatus belly. Assessment by MRI in 55 patients with rotator cuff pathology. Acta Orthop Scand 1996;67: 264-8.

43. Vaz S, Soyer J, Pries P, Clarac JP. Subacromial impingement: influence of coracoacromial arch geometry on shoulder function. Joint Bone Spine 2000;67:305-9.

44. Watanabe A, Ono Q, Nishigami T, Hirooka T, Machida H. Association between the critical shoulder angle and rotator cuff tears in Japan. Acta Med Okayama 2018;72:547-51. https://doi.org/10.18926/AMO/ 56371
45. Whitmarsh T, Humbert L, De Craene M, Del Rio Barquero LM, Frangi AF. Reconstructing the 3D shape and bone mineral density distribution of the proximal femur from dual-energy X-ray absorptiometry. IEEE Trans Med Imaging 2011;30:2101-14. https://doi.org/ 10.1109/TMI.2011.2163074

46. Yamamoto A, Takagishi K, Osawa T, Yanagawa T, Nakajima D, Shitara $\mathrm{H}$, et al. Prevalence and risk factors of a rotator cuff tear in the general population. J Shoulder Elbow Surg 2010;19:116-20. https:// doi.org/10.1016/j.jse.2009.04.006

47. Yergeau E, Poirier M. SPSS à l'UdeS [SPSS at University of Sherbrooke] [French]. 2013 [cited 2018 Jun 23]. http://spss.espaceweb. usherbrooke.ca.

48. Zhang C. Contribution à la modélisation morphofonctionnelle 3D de l'épaule [Contribution to 3D morphological modelisation of the shoulder] [French]. 2016. http://espace.etsmtl.ca/1854/. Accessed February 6, 2020. 